\title{
Digital Health and the State of Interoperable Electronic Health Records
}

Jessica Germaine Shull ${ }^{1,2}$, MSc, MA, PhD

${ }^{1} \mathrm{PhD}$ Program, Department of Biomedicine, University of Barcelona, Barcelona, Spain

${ }^{2}$ Institute for Biomedical Research Bellvitge, Hospital Bellvitge, Barcelona, Spain

\section{Corresponding Author:}

Jessica Germaine Shull, MSc, MA, PhD

$\mathrm{PhD}$ Program, Department of Biomedicine

University of Barcelona

Oficina F15 A Florensa, 8

Barcelona, 08028

Spain

Phone: 34627122319

Email: jess.shull@gmail.com

\begin{abstract}
Digital health systems and innovative care delivery within these systems have great potential to improve national health care and positively impact the health outcomes of patients. However, currently, very few countries have systems that can implement digital interventions at scale. This is partly because of the lack of interoperable electronic health records (EHRs). It is difficult to make decisions for an individual or population when the data on that person or population are dispersed over multiple incompatible systems. This viewpoint paper has highlighted some key obstacles of current EHRs and some promising successes, with the goal of promoting EHR evolution and advocating for frameworks that develop digital health systems that serve populations-a critical goal as we move further into this data-rich century with an ever-increasing number of patients who live longer and depend on health care services where resources may already be strained. This paper aimed to analyze the evolution, obstacles, and current landscape of EHRs and identify fundamental areas of hindrance for interoperability. It also aimed to highlight countries where advances have been made and extract best practices from these examples. The obstacles to EHR interoperability are not easily solved, but improving the current situation in countries where a national policy is not in place will require a focused inquiry into solutions from various sources in the public and private sector. Effort must be made on a national scale to seek solutions for optimally interoperable EHRs beyond status quo solutions. A list of considerations for best practices is suggested.
\end{abstract}

(JMIR Med Inform 2019;7(4):e12712) doi: 10.2196/12712

\section{KEYWORDS}

EHRs; health information technology; machine learning in health

\section{Introduction}

Digital health systems and innovative care delivery within these systems have great potential to improve national health care and positively impact the health outcomes of patients. However, currently, very few countries have systems that can implement digital interventions at scale. This is, in part, because of the well-known lack of interoperable electronic health records (EHRs). EHRs are the connective tissue of a health system; yet, most countries have systems that cannot unite the information of all their citizens because even within 1 city, the software used in 1 hospital is incompatible with that used in another, although it may have been procured from the same company.
Once digital health records are interoperable, digital health systems may function on a national scale rather than piecemeal or in isolation. Treatment of noncommunicable diseases could benefit from digital health coaching, personalized delivery of care, and quality of care improvements [1-3]. In addition, there may be thousands of patients who share the symptoms or side effects or respond in revealing patterns, leading to new treatments and personalized medicine, and even new disease surveillance tools could be developed [4]. However, we cannot explore or create these tools without aggregating and sharing patient data under a common set of (secure) standards. Without interoperability, using these tools or implementing remote patient monitoring products is extremely complex or simply happens in small samples. This potential use of health 
information technology has been discussed in papers dating back to 2005 [5] and analyzed for impact once EHRs were well established [6]; however, because of legacy systems and the design of those systems, the choices of EHRs are limited and incapable of algorithmic analysis across their entire client base. Epic (Epic Systems Corporation), for example, is an EHR software first designed in 1979 [7], and although the code has evolved since then, the company commands a 10 -fold price difference compared with more agile solutions with no evident improvement in quality [8]. Epic is simply the most prevalent EHR available in the United States; the company now archives at least part of the health records of approximately half the US population [8].

Partners HealthCare is a sprawling 10-hospital system in Boston, which, in 2015 to 2016, spent US \$1.2 billion [9] implementing an upgraded EHR system from Epic. The intention was to decrease errors and unify a previously disparate network that made it difficult for physicians in 1 hospital within the system to cross-reference information from a patient who had been at another [10]. When the system launched, 1000 Epic employees were required on hand to troubleshoot, which was perhaps foreseen, but the technical issues that persist today may not have been calculated. As recently as February 2019, the system was down for several hours [11], and it does not perform integration that patients are beginning to expect, such as integrating data from a connected glucose monitor. The upgrade was simply not designed with this feature. This integration is possible with a consolidation of the Apple HealthKit and the Dexcom Share2 app, as piloted on an Epic system in 2016 [12], but this extra patching work perhaps should not be required with a billion-dollar price tag. Epic is by no means alone on the list of EHR companies that are faced with a more technically savvy client base who expect better interfaces and services, and they are trying to become more agile; in 2018, the company announced One Virtual System Worldwide, which allows providers to access patient information from other institutions [13], which is a notable step but perhaps not on par with the data integration and analysis capabilities of companies such as Google and Apple.

Digital health investment is at an all-time high, with nearly US $\$ 7$ billion invested in 2018 in the United States alone [14]. However, most of the solutions being funded are not addressing the administrative foundations of the health care system such as EHRs. Investment in artificial intelligence (AI) for health care, a perhaps more tantalizing venture, is estimated to reach US $\$ 6.6$ billion by 2021 [15]. Meanwhile, the current state of real workflows at hospitals is not sustainable.

Physicians in the United States may spend half their day filling out patient histories. A 2018 study in Family Medicine found that of 982 patient visits that each lasted on average for 35.8 min, 19.3 min were spent on the EHR [16]. It is imperative that health systems gain time (and quality) where they can. In Spain, there is a notable delay to health care access; the Spanish Ministry of Health reported that in 2018, wait times for surgery had improved but were still 137 days in certain regions [17]. Systems subject to a lack of efficiency cannot afford more time, and valuable analysis is lost because of poor information systems.

\section{Machine Learning With Electronic Health Records}

$\mathrm{AI}$ is often presented as a solution to ease some of this burden. In a recent paper from Cold Spring Harbor Laboratory, numerous AI and machine learning (ML) opportunities in medicine were outlined and discussed. Among those of note were methods to classify patients according to the tests that doctors ordered for them: "Perhaps deep neural networks, by reevaluating data without the context of our assumptions, can reveal novel classes of treatable conditions [18].” To do this, however, the AI must be carefully taught with data, much or all of it coming from EHRs, that are accurate and standardized. The term garbage in, garbage out, attributed most often to George Fuechsel [19], encapsulates the biggest issue with AI and ML. The outputs of the system will inevitably reflect the quality and biases of the data fed into it. At a recent AI hackathon for health outside Barcelona in 2018, the Medical Information Mart for Intensive Care (MIMIC) database was used. It is a freely accessible database that has associated more than 53,423 admissions at a large hospital in Boston from the years 2001 to 2012 [20]. The MIMIC, MIMIC II, and MIMIC III datasets have been used numerous times to demonstrate health analytics, and explorations of ML predicted patient outcomes. However, it was stated at the event that the data took nearly 2 years to clean and this length of time is not realistic if we have to use historical and real-time data to treat patients in the present. For MIMIC, creating an interoperable database was complex; standards on how to indicate fluid intake, data from critical care information systems, and data from the Social Security Administration all had to be developed, and this was within a single hospital system.

There is no formula for the exact sample size needed in ML, although the more complex the problem, the more data needed [21]; more complex questions such as disease treatment decisions carry a high level of risk; therefore, 100,000 could be considered a reasonable starting point. If the target is to analyze a specific rare disease, such as idiopathic pulmonary fibrosis, EHRs from multiple sources would have to be accumulated to reach that number, as the disease affects 18 of every 100,000 adults [22]. Extrapolating from these statistics, if we had complete EHRs from, for example, the entire state of Texas with a population of 28.7 million, we may get information on 5000 patients - which is not nearly enough. To effectively analyze health records from patients with rare diseases and to identify indicators within those populations, the ML would need to be able to read EHRs from across the United States (population 328,929,623 as on May 23, 2019 [23]) and ideally aggregate data from other countries as well.

We are at the beginning of a data-rich and connected century. To deliver optimal care to the millions of patients who are living longer with more complex and chronic diseases, we need to harness the fundamental technology of interoperable EHRs. 


\section{Obstacles}

\section{Cost}

Health care expenditure for the entire country of Spain was more than $€ 65$ billion in 2015, according to a European Observatory on Health Systems and Policy report [24]. A US $\$ 1.2$ billion expenditure (as occurred at Partners HealthCare) to integrate 1 hospital system is not feasible in countries with fewer resources, as is the case in many single-payer systems. Solutions that do not financially cripple a health care system need to be identified. There are now companies that are harnessing the immense value of health data and are willing to implement integration and analysis systems at no cost in return for access to data [25]. This is a new frontier, akin to the new marketplace of genomic data, which likely has its own set of benefits and repercussions, and it must be analyzed as to what the implications will be.

The cost, however, should be calculated by subtracting the added value of the benefits. With properly integrated EHRs, administrative costs can be lowered, adherence rates to care protocols have shown to improve [26,27], and many in-patient visits could be achieved with remote monitoring or telehealth services. In addition, ideally, the software could scan for coding errors, which are also costly in the United States (see the section Coding and Semantics).

\section{Coding and Semantics}

The main technical issue with arriving at interoperability is the huge variation in semantics and coding standards. Hospitals code their patients differently; in our hospital, we use a case number 7 digits long, but a neighboring hospital uses their own system with 6 digits. There is a unique identifier for each patient in the regional system, but many hospitals do not enter that data at all, and that regional identifier is not used at the national level.

The Logical Observation Identifiers Names and Codes (LOINC) is an international standard used by more than 78,000 agencies and health care institutions to code for health measurements and observations [28]. However, in everyday practice, these standards are not used in EHRs. Blood pressure, for instance, in the United States, will be documented as 120/80 mm Hg. LOINC states, "They should be reported as 2 separate variables, systolic (LOINC 8480-6) and diastolic (LOINC 8462-4) [29]." That same reading will be noted as $12 / 8 \mathrm{~mm} \mathrm{Hg}$ in some European countries. In addition, blood sugar is annotated differently across borders. In the United Kingdom, blood sugar is annotated in millimoles per liter. A normal reading would be under 7.8 [30]. In the United States, blood sugar is usually written using milligrams per deciliter; therefore, a normal reading is 70 to $130 \mathrm{mg} / \mathrm{dL}$. These are simplistic examples to illustrate a fundamental concept.

There is also the conundrum of free text. Health care professionals annotate data and events in different ways. In our hospital, arterial hypertension may be listed in more than 4 ways: ht, HTA, hypertension, or hipertensió. In addition, text is used for describing symptom and disease evolution as well as test results. All these would have to be standardized or interpreted to make logical comparisons between charts. There has been an increased use of natural language processing to read free text in an EHR for disease phenotyping [31] and even detecting associations that led to adverse events [32], and it is likely this technology will be applied on a broader scale as it improves and becomes automated.

Human error is also a consideration. Within 1 country, there may be discrepancy among codes for diagnosis. When International Classification of Diseases (ICD), Tenth Revision, Clinical Modification (ICD-10-CM) replaced ICD-9 in the United States in 2015, the coding options increased 10-fold, from 14,400 to 144,000 [33]. The ICD-10-CM codes were linked to reimbursement for health care services, which made it all the more critical that codes be correct because mistakes could be taken as fraud. The Centers for Medicare and Medicaid Services released data indicating preventable billing errors had cost US $\$ 31.6$ billion in 2018 [34]. However, it has been found that 1 ICD-9 code could be interpreted as 100 different ICD-10-CM codes, and not all of these codes seem logical: Y92.241, hurt at the library; W56.22, struck by Orca, initial encounter [33]. The United States is the only country that uses ICD-10-CM, creating yet another layer of incompatibility. If we had global compatibility of ICD coding, the statistics for global health would be far more accurate, which could, in theory, shift treatment protocols by allocating resources more precisely or seeing new trends in both communicable and noncommunicable diseases.

\section{Privacy Issues}

Privacy and security for health care data are of utmost importance. Effort must be made to educate health care administrations on how EHRs work, why they can be considered as safe as banking data, and what cybersecurity checks are in place and emphasize the importance of a continually updated security plan. Often, it is not a real security risk that needs to be addressed but the perception of risk [35]. Blockchain or other technologies should be analyzed for use, and more importantly, personnel who are equipped to detect and patch issues as well as develop solutions should be on staff.

\section{Analysis of Progress}

Over the years, there have been substantial efforts in the advocacy for EHR systems to integrate their internal sources of data as well as myriad external sources of patient information. Exemplary work from Mandl and Kohane in 2009 petitioned for EHRs and personally controlled health records to be built on open standards, accommodating both open-source and closed-source software, including data generated by a patient's iPhone [36]. The authors advocated as well for federal support to clear the financial and taxonomic barriers to achieve this asking, "Can we produce a medication list for every American that can be obtained through standards-based, interoperable, substitutable applications?" The answer then was no, but open standards efforts are currently being developed and used internationally.

For instance, there is now RxNorm from the US National Library of Medicine, which can mediate messages between systems not using the same software and vocabulary, linking names of clinical drugs and drug interaction software [37]. 
Fast Health Interoperability Resources (FHIR) from HL7 is now widely recognized as the standard for EHR integration; it is used by Google for its Cloud Healthcare API stating that "FHIR specifies a robust, extensible data model for interacting with clinical resources" [38]. Analysis of data from Centers for Medicare \& Medicaid Services and the Office of the National Coordinator for Health Information Technology in 2018 revealed that $32 \%$ of health information technology developers in the United States are using 2015 FHIR-certified standards, and the biggest EHR companies (including Epic and Cerner) are to some extent using FHIR standards [39]. Microsoft announced their Azure API for FHIR in February 2019 [40], and FHIR standards are also being used for the integration of wearables data and personalized devices [41]. SMART for FHIR is a project, which started in 2010 (FHIR was defined during the project) at Harvard Medical School and Boston Children's Hospital, aimed for medical applications to run without modifications across disparate health information systems. Mandel et al. demonstrated that within 2 months, a couple of software engineers could implement SMART on FHIR for 4 different EHR vendors [42].

In January 2018, Apple announced their version of a personalized EHR called HealthKit [43], which patients can access on their iPhone; it would appear Apple understands the value of providing a service that is user-friendly and that patients can monitor themselves and integrate data from fitness devices that connect to Apple.

\section{Examples of Innovation in National Electronic Health Record Systems}

Most countries in the world now use digital health records to some extent. The author of this paper (JS) collaborated with a team from the World Health Organization that was implementing a digital health information system in Sierra Leone in 2007, chosen precisely because it was a nearly entirely paper-based system and therefore a blank canvas. Since then much more infrastructure has been installed, and Sierra Leone has implemented district health information software from HISP in large hospital centers; in 2016, during the Ebola outbreak, a specialized EHR based on OpenMRS was developed for the Ebola treatment centers [44].

Rwanda began implementing OpenClinic electronic medical record in 2007, and it is now used throughout the country, in 20 hospitals and clinics [45]. In 2016, the Rwandan Ministry of Health partnered with Babylon Health, a company that now offers electronic prescriptions and telephone consultations to the now more than 2 million subscribers [46]. In addition, users can access their clinical records anytime via their phone, including images and audio and video of the consultations.

Estonia is another country where significant advances in health information technology innovation have been deployed at scale. The government launched an effort in 2016 to implement blockchain validation into the national EHR [47], the first country in the world to do so. The technology ensures data integrity and substantially reduces the risk of malicious intent or hacking because of blockchain's immutable data logs. This addresses the aforementioned issue of security, often cited by health care administrations when the question of electronic health data sharing is discussed.

In 2016, the Thai Health Information Standards Development Center published a plan for adopting national standards for patient health care summary, laboratory terminology (LOINC), syntax (HL7), and security (MICT) [48]. Thailand has already been notably forward-thinking by creating a unique national identifier system and achieving universal health care coverage in 2002 [49]; hence, the country is familiar with the effort it takes to align all the stakeholders involved in this type of initiative.

Israel has an integrated health monitoring system covering 4.2 million patients [50]. Since the implementation, studies have shown that patients are more adherent to medications [51].

In January 2019, Abu Dhabi launched a unified health information exchange platform called Malaffi, which allows approximately 2000 public and private health care providers across the Emirates to access and share information for approximately 3 million people [52]. This top-down approach is very effective when there are adequate funds to enact the process, but not possible in a country similar to the United States, where there is no single authority for a very disparate private health care system.

Belgium has coordinated an interoperable health record for all citizens, which came to full implementation in 2019, called MijnGezondheid [53]. Patient records can now be seen by any physician in any hospital in the country, not an easy feat when considering it includes all periphery hospitals, mental health institutions, pharmacies, and laboratory systems in 2 languages across 3 regions.

\section{Viewpoint on Best Practices}

All stakeholders within a health system can participate in shaping EHRs to be useful and evolved. The following are considerations for establishing best practices for effective and interoperable EHRs.

\section{Standards}

Adopt international standards such as FHIR, LOINC, and SNOMED CT and introduce these standards starting in medical school and university informatics classes. There should be International Standard Organizations standards required of any wearable that is integrated into an EHR so that physicians can be assured the data are reliable. For instance, a 6-m walking test may be performed by a patient at home and recorded for reference, but the results must be obtained by a device that has been proven to have accurate readings in a clinical setting. This is integral to the policy work on digital health regulation.

\section{Education and Awareness}

It is the responsibility of health care administrations to understand interoperability obstacles, the benefits of achieving this, and how it may be done. Investigation is required. In addition, a top-down approach is not the only effective means for adoption of interoperable EHRs. Citizen scientists are constantly developing their own hacks for integration of digital 
health data, and indeed everyone, from patients to surgeons and from physiotherapists, nurses, to the billing office, should be involved or at least aware of the design process as it affects them all. Use the principle of user experience design and the way that all digital health platforms should be developed: know your user. A software developer may not intuit a cardiologist's needs (for instance, fast access to images and laboratory results) as opposed to a general practitioner (perhaps most important is an immediate view of history and medications); therefore, physicians, nurses, and administrators must be there to advise and do testing. Physicians can bring solutions that work to hospital administration, highlighting the benefits. On the other side, information technology professionals should be aware of how reimbursement works (among a myriad of other processes) and who needs to see what information when, including the entire arc of care from home caretakers to statisticians.

Ensure awareness of wearables and other sensor data and the fact that eventually patients will likely want this information to be incorporated into their EHR. The new companies developing EHR integration software must also be discerning of the quality and clinical validity of data being integrated.

\section{Privacy}

Hospital administration should request education on privacy and cybersecurity issues, and perhaps, ministries of health should offer short courses to strengthen their knowledge base. Ideally, hospital administration will feel comfortable in considering innovative solutions such as blockchain or in hiring the appropriate people who can, to ensure security and integrity of all patients' health data.

Hospital administration, ministries of health, and the general public should know how to access their data, how data are protected, and what the data can do for them. Perhaps there can be public service announcements on television, radio, and social media.

\section{Alternative Solutions}

Although the importance of interoperability seems to be a concept now recognized by the large EHR vendors, alternative and economically feasible solutions should be considered by health care administrations. There are solutions that do not require an entire retrofit of a hospital system to deliver data, which avoids the issue of interoperability altogether: Redox, which states it is Health Insurance Portability and Accountability Act compliant and secure, can intake HL7, FHIR, CDA, or X12 data, combine the data, and deliver an output [54].

Seqster is a company that officially entered the marketplace in 2018 and claims to be, "the only technology capable of enabling the majority of 350 million Americans to instantly connect to their EHR(s) along with major fitness/wearable devices, and consumer genetic labs" [55]. They have managed to aggregate and unify health information coming from Epic, Cerner, Strava, and even Fitbit.

There are likely many more companies that will appear in the marketplace as the value is increasingly recognized for having interoperable, clean, and accurate health records that can be data mined for life-saving decision making, research, and public health policy.

\section{Author's Note}

Since the writing of this article, Smart on FHIR has been implemented in over 100 Epic sites, and the trend is continuing.

\section{Acknowledgments}

The author would like to thank Bellvitge Hospital in Barcelona, Dr Maria Molina, Coordinator of the Interstitial Pulmonary Unit at Bellvitge Hospital and professor at the University of Barcelona, and the digital health community for all the work in this sphere.

\section{Conflicts of Interest}

The author consulted for the Digital Therapeutics Alliance, a nonprofit trade association for the digital therapeutics industry.

\section{References}

1. Sharma A, Harrington RA, McClellan MB, Turakhia MP, Eapen ZJ, Steinhubl S, et al. Using digital health technology to better generate evidence and deliver evidence-based care. J Am Coll Cardiol 2018 Jun 12;71(23):2680-2690 [FREE Full text] [doi: 10.1016/j.jacc.2018.03.523] [Medline: 29880129]

2. Kruse C, Pesek B, Anderson M, Brennan K, Comfort H. Telemonitoring to manage chronic obstructive pulmonary disease: systematic literature review. JMIR Med Inform 2019 Mar 20;7(1):e11496 [FREE Full text] [doi: 10.2196/11496] [Medline: $\underline{30892276]}$

3. Prahalad P, Tanenbaum M, Hood K, Maahs D. Diabetes technology: improving care, improving patient-reported outcomes and preventing complications in young people with type 1 diabetes. Diabet Med 2018 Apr;35(4):419-429. [doi: 10.1111/dme.13588] [Medline: 29356074]

4. Yang CY, Chen RJ, Chou WL, Lee YJ, Lo YS. An integrated influenza surveillance framework based on national influenza-like illness incidence and multiple hospital electronic medical records for early prediction of influenza epidemics: design and evaluation. J Med Internet Res 2019 Feb 1;21(2):e12341 [FREE Full text] [doi: 10.2196/12341] [Medline: 30707099]

5. Hillestad R, Bigelow J, Bower A, Girosi F, Meili R, Scoville R, et al. Can electronic medical record systems transform health care? Potential health benefits, savings, and costs. Health Aff (Millwood) 2005;24(5):1103-1117. [doi: 10.1377/hlthaff.24.5.1103] [Medline: 16162551] 
6. Miriovsky BJ, Shulman LN, Abernethy AP. Importance of health information technology, electronic health records, and continuously aggregating data to comparative effectiveness research and learning health care. J Clin Oncol 2012 Dec 1;30(34):4243-4248. [doi: 10.1200/JCO.2012.42.8011] [Medline: 23071233]

7. Epic Systems. 2019. Epic: About URL: https://www.epic.com/about [accessed 2019-05-26]

8. Koppel R, Lehmann C. Implications of an emerging EHR monoculture for hospitals and healthcare systems. J Am Med Inform Assoc 2015 Mar;22(2):465-471. [doi: 10.1136/amiajnl-2014-003023] [Medline: 25342181]

9. McCluskey PD. The Boston Globe. 2016. Mass. General Launches Epic Health Records Upgrade URL: https://www. bostonglobe.com/business/2016/04/05/epic-upgrade-mass-general/9NIikFtLwWS8rysvZOxxyH/story.html [accessed 2018-10-30]

10. McCluskey PD. The Boston Globe. 2015. Partners' \$1.2b Patient Data System Seen as Key to Future URL: https://www. bostonglobe.com/business/2015/05/31/partners-launches-billion-electronic-health-records-system/ oo4nJJW2rQyfWUWQlvydkK/story.html [accessed 2019-05-27]

11. Vaidya A. Becker's Hospital Review. 2019. Partners Experiences Technical Issues, Including EHR Downtime URL: https:/ /www.beckershospitalreview.com/ehrs/partners-experiences-technical-issues-including-ehr-downtime.html [accessed 2019-05-27]

12. Kumar RB, Goren ND, Stark DE, Wall DP, Longhurst CA. Automated integration of continuous glucose monitor data in the electronic health record using consumer technology. J Am Med Inform Assoc 2016 May;23(3):532-537 [FREE Full text] [doi: 10.1093/jamia/ocv206] [Medline: 27018263]

13. Arndt RZ. Modern Healthcare. 2018. For Epic, Interoperability Comes From Within URL: https://www. modernhealthcare.com/article/20180130/NEWS/180139993/for-epic-interoperability-comes-from-within [accessed 2018-10-01]

14. Zweig M. Rock Health. 2018. Q3 2018: An Entrepreneurs' Market Leads to Digital Health's Biggest Quarter Yet URL: https://rockhealth.com/reports/q3-2018-an-entrepreneurs-market-leads-to-digital-healths-biggest-quarter-yet/ [accessed 2018-10-30]

15. Forbes Magazine. 2019. AI And Healthcare: A Giant Opportunity URL: https://www.forbes.com/sites/insights-intelai/2019/ 02/11/ai-and-healthcare-a-giant-opportunity/ [accessed 2019-05-27]

16. Young RA, Burge SK, Kumar KA, Wilson JM, Ortiz DF. A time-motion study of primary care physicians' work in the electronic health record era. Fam Med 2018 Feb;50(2):91-99 [FREE Full text] [doi: 10.22454/FamMed.2018.184803] [Medline: 29432623]

17. Guell O. El País. 2018. Surgery Waiting Times in Spain: 93 Days, Slightly Down From 2017 URL: https://elpais.com/ elpais/2018/11/29/inenglish/1543509744_110649.html [accessed 2019-05-23]

18. Ching T, Himmelstein DS, Beaulieu-Jones BK, Kalinin AA, Do BT, Way GP, et al. Opportunities and obstacles for deep learning in biology and medicine. J R Soc Interface 2018 Apr;15(141):20170387 [FREE Full text] [doi: 10.1098/rsif.2017.0387] [Medline: 29618526]

19. Lidwell W, Holden K, Butler J. Universal Principles of Design: 125 Ways to Enhance Usability, Influence Perception, Increase Appeal, Make Better Design Decisions, and Teach through Design. Beverly, MA: Rockport Publishers; 2010.

20. Johnson AE, Pollard TJ, Shen L, Lehman LH, Feng M, Ghassemi M, et al. MIMIC-III, a freely accessible critical care database. Sci Data 2016 May 24;3:160035 [FREE Full text] [doi: 10.1038/sdata.2016.35] [Medline: 27219127]

21. Brownlee J. Machine Learning Mastery. 2017. How Much Training Data is Required for Machine Learning? URL: https:/ /machinelearningmastery.com/much-training-data-required-machine-learning/ [accessed 2019-05-29]

22. Raghu G, Chen SY, Hou Q, Yeh WS, Collard HR. Incidence and prevalence of idiopathic pulmonary fibrosis in US adults 18-64 years old. Eur Respir J 2016 Jul;48(1):179-186 [FREE Full text] [doi: 10.1183/13993003.01653-2015] [Medline: 27126689]

23. United States Census Bureau. 2019. US and World Population Clock URL: https://www.census.gov/popclock/ [accessed 2019-05-23]

24. Bernal-Delgado E, García-Armesto S, Oliva J, Sánchez-Martinez FI, Repullo JR, Peña-Longobardo LM, et al. WHO/Europe. 2018. Spain Health System Review 2018 URL: http://www.euro.who.int/ data/assets/pdf file/0008/378620/hit-spain-eng. pdf?ua=1 [accessed 2019-05-24]

25. Stacey J. ACRP: Association of Clinical Research Professionals. 2017. Using EHR Data Extraction to Streamline the Clinical Trial Process URL: https://acrpnet.org/2017/04/01/using-ehr-data-extraction-streamline-clinical-trial-process/ [accessed 2019-05-28] [WebCite Cache ID 78hbcawTv]

26. Evans RS. Electronic health records: then, now, and in the future. Yearb Med Inform 2016 May 20(Suppl 1):S48-S61 [FREE Full text] [doi: 10.15265/IYS-2016-s006] [Medline: 27199197]

27. Kazley AS, Simpson A, Simpson K, Teufel R. Association of electronic health records with cost savings in a national sample. Am J Manag Care 2014 Jun 1;20(6):e183-e190 [FREE Full text] [Medline: 25180501]

28. LOINC. URL: https://loinc.org/ [accessed 2019-05-27]

29. 55284-4 - LOINC Details. 2018. 55284-4 - Blood Pressure Systolic and Diastolic URL: https://r.details.loinc.org/LOINC/ 55284-4.html?sections=Comprehensive [accessed 2019-05-27] 
30. Diabetes UK. 2019. Blood Sugar Level Ranges URL: https://www.diabetes.co.uk/diabetes_care/blood-sugar-level-ranges. html [accessed 2019-05-27]

31. Sheikhalishahi S, Miotto R, Dudley JT, Lavelli A, Rinaldi F, Osmani V. Natural language processing of clinical notes on chronic diseases: systematic review. JMIR Med Inform 2019 Apr 27;7(2):e12239 [FREE Full text] [doi: 10.2196/12239] [Medline: $\underline{31066697]}$

32. Wong A, Plasek J, Montecalvo S, Zhou L. Natural language processing and its implications for the future of medication safety: a narrative review of recent advances and challenges. Pharmacotherapy 2018 Aug;38(8):822-841. [doi: 10.1002/phar.2151] [Medline: 29884988]

33. Manchikanti M, Kaye AD, Singh V, Boswell MV. The tragedy of the implementation of ICD-10-CM as ICD-10: is the cart before the horse or is there a tragic paradox of misinformation and ignorance? Pain Physician 2015;18(4):E485-E495 [FREE Full text] [Medline: 26218946]

34. Council for Medicare Integrity. 2018. Error Rate Drops, but Medicare Still Lost \$31.6 Billion to Preventable Billing Errors in FY2018 URL: http://medicareintegrity.org/ error-rate-drops-but-medicare-still-lost-31-6-billion-to-preventable-billing-errors-in-fy2018/ [accessed 2019-05-28]

35. Shahbaz M, Gao C, Zhai L, Shahzad F, Hu Y. Investigating the adoption of big data analytics in healthcare: the moderating role of resistance to change. J Big Data 2019 Jan 31;6(1):6 [FREE Full text] [doi: 10.1186/s40537-019-0170-y]

36. Mandl KD, Kohane IS. No small change for the health information economy. N Engl J Med 2009 Mar 26;360(13):1278-1281. [doi: 10.1056/NEJMp0900411] [Medline: 19321867 ]

37. National Library of Medicine - National Institutes of Health. 2019. Unified Medical Language System® (UMLS®): RxNorm URL: https://www.nlm.nih.gov/research/umls/rxnorm/ [accessed 2019-09-14]

38. Google Cloud. 2019. Cloud Healthcare API URL: https://cloud.google.com/healthcare/ [accessed 2019-09-14]

39. Posnack S, Barker W. HealthIT. 2018. Heat Wave: The US is Poised to Catch FHIR in 2019 URL: https://www.healthit.gov/ buzz-blog/interoperability/heat-wave-the-u-s-is-poised-to-catch-fhir-in-2019 [accessed 2019-05-28]

40. Cartwright HJ. Microsoft Azure Cloud Computing Platform \& Services. 2019. Lighting Up Healthcare Data With FHIR®: Announcing the Azure API for FHIR URL: https://azure.microsoft.com/en-us/blog/ lighting-up-healthcare-data-with-fhir-announcing-the-azure-api-for-fhir/ [accessed 2019-05-28]

41. Saripalle RK. Leveraging FHIR to integrate activity data with electronic health record. Health Technol 2019 Apr 27:[FREE Full text] [doi: 10.1007/s12553-019-00316-5]

42. Mandel JC, Kreda DA, Mandl KD, Kohane IS, Ramoni RB. SMART on FHIR: a standards-based, interoperable apps platform for electronic health records. J Am Med Inform Assoc 2016 Sep;23(5):899-908 [FREE Full text] [doi: 10.1093/jamia/ocv189] [Medline: 26911829]

43. Apple Newsroom. 2018. Apple Announces Effortless Solution Bringing Health Records to iPhone URL: https://www. apple.com/newsroom/2018/01/apple-announces-effortless-solution-bringing-health-records-to-iPhone/ [accessed 2019-05-27]

44. Oza S, Jazayeri D, Teich JM, Ball E, Nankubuge PA, Rwebembera J, et al. Development and deployment of the OpenMRS-Ebola electronic health record system for an Ebola treatment center in Sierra Leone. J Med Internet Res 2017 Aug 21;19(8):e294 [FREE Full text] [doi: 10.2196/jmir.7881] [Medline: 28827211]

45. Uwambaye P, Njunwa K, Nuhu A, Kumurenzi A, Isyagi M, Murererehe J, et al. Health care consumer's perception of the electronic medical record (EMR) system within a referral hospital in Kigali, Rwanda. RWJour 2017 May 24;4(1):48. [doi: 10.4314/rj.v4i1.7f]

46. Babyl Health Rwanda. 2018. URL: http://www.babyl.rw/ [accessed 2019-05-28]

47. Angraal S, Krumholz HM, Schulz WL. Blockchain technology: applications in health care. Circ Cardiovasc Qual Outcomes 2017 Sep;10(9):e003800. [doi: 10.1161/CIRCOUTCOMES.117.003800] [Medline: 28912202]

48. Kijsanayotin B, Benchakittipakorn P. Bureau of Thai Health Information System Standards Development. 2016. eHealth in Thailand: Interoperability and Health Information Standards URL: http://www.this.or.th/files/interopbook.pdf [accessed 2019-04-27]

49. Jongudomsuk P, Srithamrongsawat S, Patcharanarumol W, Limwattananon S, Pannarunothai S, Vapatanavong P, et al. Newborn and Birth Defects Database. 2015. The Kingdom of Thailand Health System Review URL: http://apps.searo.who.int/ PDS DOCS/B5410.pdf [accessed 2019-05-27]

50. Thorne M. Allscripts. 2017. Israel: A Case Study in National Connectivity for Better Health URL: https://www.allscripts.com/ File\%20Library/Case\%20Studies/Clalit-Health-Services.pdf [accessed 2019-05-28]

51. Srulovici E, Garg V, Ghilai A, Feldman B, Hoshen M, Balicer RD, et al. Is patient support program participation associated with longer persistence and improved adherence among new users of adalimumab? A retrospective cohort study. Adv Ther 2018 May;35(5):655-665. [doi: 10.1007/s12325-018-0706-0] [Medline: 29748914]

52. Department of Health - Abu Dhabi. 2019. DoH Launches 'Abu Dhabi Health Information Exchange' to Integrate Technological Transformations in Healthcare URL: https://www.haad.ae/haad/tabid/58/ctl/Details/Mid/417/ItemID/808/ Default.aspx [accessed 2019-05-29]

53. Mijngezondheid. URL: https://home.mijngezondheid.net/ [accessed 2019-09-17]

54. Redox. 2019. Revamp Legacy Infrastructure for a Digital World URL: https://www.redoxengine.com/provider-organizations/ [accessed 2019-05-28] [WebCite Cache ID 78hhXumSU] 
55. Seqster | We Seek Clarity For Health Data. 2019. URL: https://seqster.com/ [accessed 2019-05-28]

\section{Abbreviations}

AI: artificial intelligence

EHR: electronic health record

FHIR: Fast Health Interoperability Resources

ICD: International Classification of Diseases

LOINC: Logical Observation Identifiers Names and Codes

MIMIC: Medical Information Mart for Intensive Care

ML: machine learning

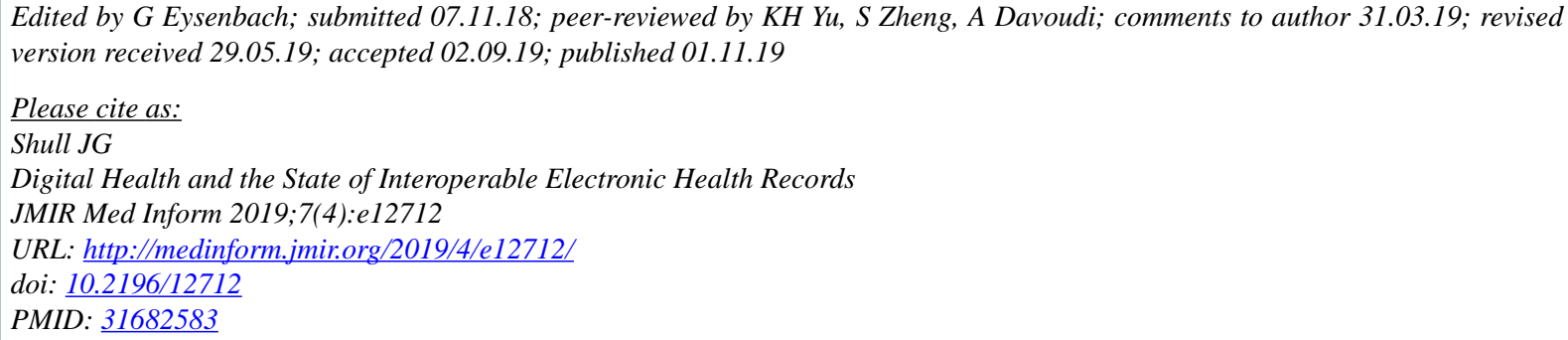

(CJessica Germaine Germaine Shull. Originally published in JMIR Medical Informatics (http://medinform.jmir.org), 01.11.2019. This is an open-access article distributed under the terms of the Creative Commons Attribution License (https://creativecommons.org/licenses/by/4.0/), which permits unrestricted use, distribution, and reproduction in any medium, provided the original work, first published in JMIR Medical Informatics, is properly cited. The complete bibliographic information, a link to the original publication on http://medinform.jmir.org/, as well as this copyright and license information must be included. 